\title{
Towards circular economy implementation in manufacturing systems using a multi-method simulation approach to link design and business strategy
}

\author{
Michael Lieder $^{1}$ - Farazee M. A. Asif ${ }^{1} \cdot$ Amir Rashid $^{1} \cdot$ Aleš $^{\text {Mihelič }}{ }^{2} \cdot$ Simon Kotnik $^{3}$
}

Received: 15 February 2017 / Accepted: 5 June 2017 / Published online: 23 June 2017

(C) The Author(s) 2017. This article is an open access publication

\begin{abstract}
The recent circular economy movement has raised awareness and interest about untapped environmental and economic potential in the manufacturing industry. One of the crucial aspects in the implementation of circular or closedloop manufacturing approach is the design of circular products. While it is obvious that three post-use strategies, i.e., reuse, remanufacturing, and recycling, are highly relevant to achieve loop closure, it is enormously challenging to choose "the right" strategy (if at all) during the early design stage and especially at the single component level. One reason is that economic and environmental impacts of adapting these strategies are not explicit as they vary depending on the chosen business model and associated supply chains. In this scenario,
\end{abstract}

Electronic supplementary material The online version of this article (doi:10.1007/s00170-017-0610-9) contains supplementary material, which is available to authorized users.

Amir Rashid

amirr@kth.se

Michael Lieder

lieder@kth.se

Farazee M. A. Asif

aasi@kth.se

Aleš Mihelič

ales.mihelic@gorenje.com

Simon Kotnik

simon.kotnik@gorenje.com

1 Department of Production Engineering, KTH Royal Institute of Technology, Brinellvägen 68, SE-100 44 Stockholm, Sweden

2 R\&D Competence Centre Laundry Care, Gorenje d.d., Partizanska 12, SI-3320 Velenje, Slovenia

3 Joint R\&D Centre, Gorenje d.d., Partizanska 12, SI-3320 Velenje, Slovenia decision support is essential to motivate adaptation of regenerative design strategies. The main purpose of this paper is to provide reliable decision support at the intersection of multiple lifecycle design and business models in the circular economy context to identify effects on cost and $\mathrm{CO}_{2}$ emissions. The development of this work consists of a systematic method to quantify design effort for different circular design options through a multi-method simulation approach. The simulation model combines an agent-based product architecture and a discrete event closed-loop supply chain model. Feasibility of the model is tested using a case of a washing machine provided by Gorenje d.d. Firstly, design efforts for reuse, remanufacturing, and recycling are quantified. Secondly, cost and emissions of different design options are explored with different business model configurations. Finally, an optimization experiment is run to identify the most cost-effective combination of reused, remanufactured, and recycled components for a business model chosen on the basis of the explorative study results.

Keywords End-of-life design strategy $\cdot$ Closed-loop manufacturing system · Circular economy $\cdot$ Business model · Supply chain $\cdot$ Multi-method simulation

\section{Introduction}

The recent circular economy (CE) movement has raised awareness as well as interest about untapped environmental and economic potential in manufacturing industry. In this context, the design of closed-loop manufacturing systems capable of closing the loop by intention rather than by chance has received increasing attention $[1,2]$. However, to the largest extent so far, $\mathrm{CE}$ research has been carried out from the perspectives of end-of-life (EoL) waste, resource use, and 
environmental impact while leaving business and economic perspectives rather unexplored [3]. From industrial perspective, a transition from a linear (take-make-dispose) to a closedloop or circular system requires a move from the conventional model of selling physical products to selling access to functionality or service. In such service-based business models, including leasing or pay-per-use, the manufacturers retain ownership of their products and take them back after use for the purpose of value recovery and redistribution. As a consequence, post-use design strategies like reuse, remanufacturing, and recycling become highly relevant for the CE implementation process as they practically enable loop closure and influence cost and emissions of operational value recovery. These circumstances bring manufacturing companies to an uncertain position when it comes to CE approaches since the potentials of their product design in combination with new (circular) business models are not known.

There are sophisticated tools available for designers which provide decision support during the design process in terms of cost estimates, lifecycle assessment, and material criticality. However, most of these tools are limited to the scope of linear production, i.e., used by one user for one life neglecting recovery activities. At this point, it becomes enormously challenging for designers and decision-makers to estimate economic and environmental benefits of design options in an expanded and unexplored $\mathrm{CE}$ view.

One approach to promote an industrially driven CE consists of simultaneous consideration of product design, business models, and supply chains [1]. Based on this systemic perspective, Fig. 1 illustrates explorative and optimization approaches. The explorative approach assumes that there is not any preknowledge available. Starting point is therefore the designer who allocates different end-of-life strategies to components. As a next step, the additional design effort in terms of cost or $\mathrm{CO}_{2}$ emissions to realize the chosen design needs to be specified. Finally, the business model through which the product is going to be delivered is decided. By going through these steps multiple times with different constellations allows for systematic exploration of design and business potentials. The other way around, the best fitting design strategy for one particular circular business model can be supported by optimization approaches. If the relevant business model has been chosen and the maximum additional design effort (e.g., budget) decided, it is possible to obtain the best fitting (e.g., cost-minimum) allocation of EoL strategies on component level. Both approaches connect design as well as business strategy and treat supply chain as implicit but central part. To date, tools are missing which provide an objective approach to guide decisionmaking from this comprehensive and systemic perspective in a quantifiable manner.

In the given context, the objective of this research is to develop a multi-method simulation tool to assist the CE paradigm and enable assessments of circular design strategies on component level considering various $\mathrm{CE}$ business models. There are three elements on which the tool has been based on: (1) method to systematically quantify design efforts for different circular design options, (2) multi-method model (MMM) development using agent-based ( $\mathrm{AB})$ and discrete event (DE) approaches, (3) computer simulation to demonstrate combined effects of design options and CE business models.

The applicability of the tool is demonstrated through an illustrative case scenario using a washing machine example from the company Gorenje d.d. which has provided the product data for this study. The case tests different circular design strategies including reuse/remanufacturing/recycling at component level in a buy-back, leasing, and pay-per-use supply chain setting. The resulting MMM is supposed to provide insights on cost effects and environmental impact $\left(\mathrm{CO}_{2}\right.$ emissions) and therewith facilitate decision-making for industrial organizations shifting from linear to circular systems. The remainder of this paper is structured as follows:

Section 2 Discusses the state of the art review

Section 3 The introduction of the concepts which are at the basis of this work

Section 4 The formulation of the MMM

Section 5 The description of the case scenario using the example of a washing machine

Section 6 The presentation and discussion of the simulation results

Section 7 The conclusions and research outlook

\section{State of the art review on design evaluation methods}

A literature review has been carried out to identify relevant contributions in methods for design evaluation, particularly in the light of economic and environmental impacts.

\subsection{Product cost estimation}

Product cost estimation has naturally been of high relevance for industrial businesses as the largest share of cost is committed at the early design phase [4]. Typically, lifecycle costing (LCC) is used as framework in order to quantify cost of development, production, use, and retirement of a product [5]. In order to also account for environmental impacts, lifecycle assessment (LCA) has become an established approach in research and practice [6]. Efforts have been made to merge both LCC and LCA to one more comprehensive assessment approach [7-9]. Material and lifecycle engineering (LCE) have also been investigated [10]. A classification of qualitative and quantitative techniques on product cost estimation for manufacturing businesses can be found in the article of Niazi et al. [11]. Here, cost estimation 


\section{Explorative approach}

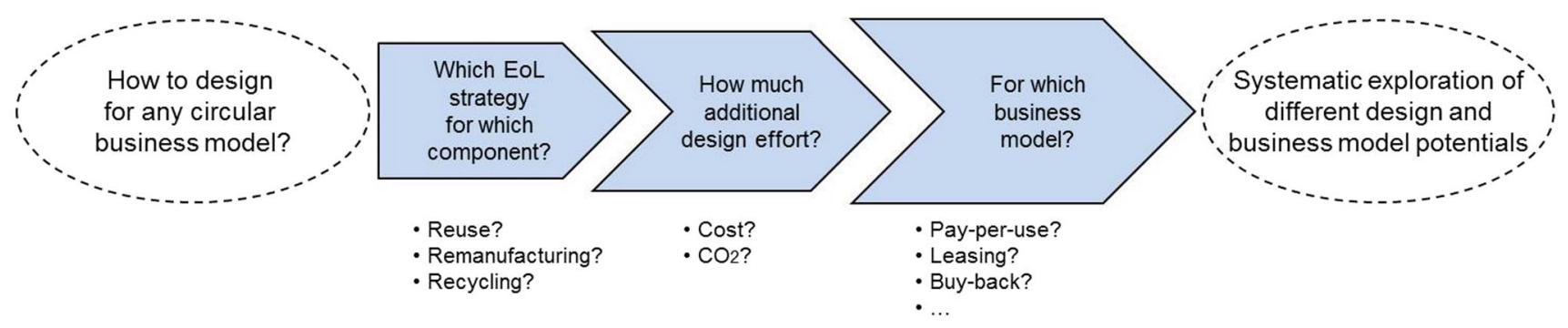

Optimization approach

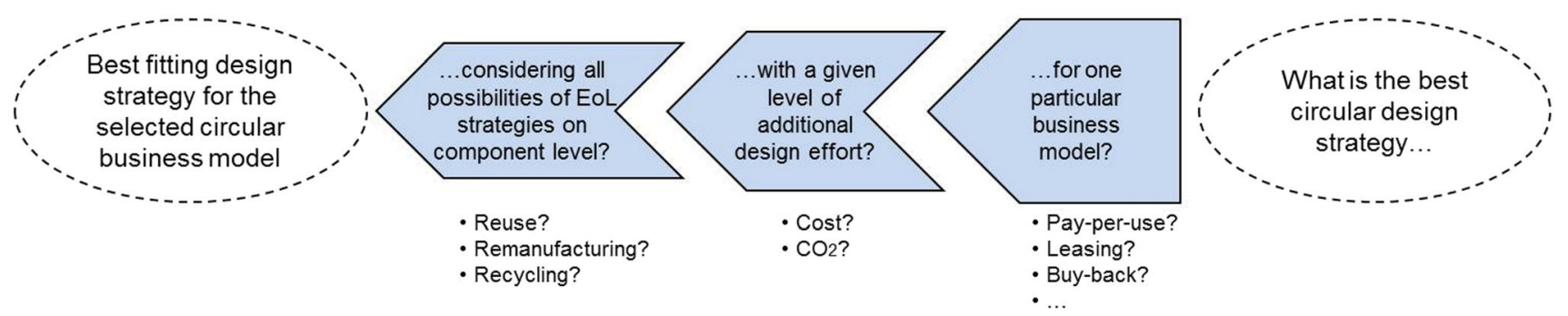

Fig. 1 Explorative approach and optimization approach to connect design and business strategy in a CE

techniques have been categorized according to analogical, parametrical, and analytical approaches as well as to early design stages and specific applications. In this context, cost estimations at early design stage stay on qualitative level as predictions of future expenses are made based on past data.

\subsection{End-of-life strategies}

For the past two decades, design approaches have gradually started to put more focus on the retirement phase of products. Particularly disassembly processes have been discussed in the engineering domain and associated with environmental gains as well as efficient activities of reuse, remanufacturing, and recycling [12-14]. Latest research in this area emphasizes consideration of relevant methodologies and technologies at early design stage [15] and design towards multiple generation lifecycles [16]. Different EoL strategies for reuse, remanufacturing, and recycling have been explored under consideration of modular product architectures [17, 18]. In these approaches, components that have similar characteristics were grouped to form modules in order to simplify the EoL operations such as remanufacturing. These evaluation methods are supportive in identifying economic and environmental gains of reengineering and redesign efforts in a given business setting.

\subsection{Simulation techniques}

Simulation techniques have proven to be useful, predominantly in the manufacturing domain, to facilitate cost forecasting for specific parts and products [19]. In general, discrete event models have been recognized as an established approach when it comes to modeling processes and estimating cost $[20,21]$. Hence, it can be emphasized that simulation techniques at early design phase can be supportive in connecting design concepts and their implications on operational cost.

\subsection{Discussion of the state of the art}

In general, there is increasing interest in the area of sustainable manufacturing and key enabling technologies [22]. Even if contributions show that reuse, remanufacturing, and recycling are part of today's design research, it can be concluded that the motivation of considering these EoL strategies is mostly rooted in environmental awareness and concerns. This is especially the case for remanufacturing [23] and during conceptual design stage [24]. As a consequence, the recovery of products appears not to be part of a pre-defined business strategy, but rather pursued ex post in order to recover unanticipated value. While traditional approaches such as LCA or analytical cost calculations stay within the linear paradigm, a number of conceptual frameworks have recently been developed $[25,26]$. These developments highlight product design and business model strategies for companies in $\mathrm{CE}$ context. Although these contributions are useful in understanding the link between product design and business aspects, they provide little support in the process of implementation.

There have been simulation efforts to link design choices as well as supply and demand in a multiple product lifecycle scenarios [27]. However, these efforts do not connect business 
strategy of a company with users of products in a systemic manner. They rather focus on the linear consumption behavior in terms of disposal factors and maintenance cost. Due to the gap between business operations and users, the recovery of products appears to be an opportunity-based activity rather than an intended business strategy. As a natural consequence, uncertainty arises when it comes to quality, quantity, and timing of product returns, which hinders further implementation steps.

In summary, decision support for designers is missing which is capable of connecting design and business strategy. The assessment of different EoL strategies at the intersection of design options and business models in a quantifiable manner would enable designers in industry to gain insight into circular business potentials. In doing so, concrete design choices on component level need to be connected to operational cost and emissions on supply chain level to allow for assessment of economic and environmental impact. In the following section, this need is addressed by two features: (1) a method to systematically quantify design efforts for different circular design options and (2) a multi-method model capable of capturing the movement of components through different circular supply chains and business settings to quantify cost and $\mathrm{CO}_{2}$ emissions. These two features will enable systematic exploration of design and business potentials as well as optimization of EoL strategies on component level in given manufacturing system settings.

\section{End-of-life design concepts}

\subsection{Product design index}

In the context of circular systems, definitions for product design attributes at the EoL are required. A suitable design index approach is provided by Asif et al. to conceptualize and assess economic and environmental impacts of circular product systems [2]. In this design index approach, physical lifetime and use lifetime of products are differentiated to consider possible end-of-life strategies on product level. Physical lifetime is defined as the average lifetime before a product experiences functional failure (objective obsolescence) while use lifetime stands for the average time before a product becomes unwanted (subjective obsolescence).

In practice, physical lifetime and EoL strategy of different components in a product are decided by product designers towards the end of the design phase. At this point, designers are capable of estimating the physical lifetime, i.e., the functional failure of the product. Additionally, designers choose the EoL strategy based on the bill of material (BoM), i.e., the components of the product which can be recycled and/or landfilled. These design decisions for recycling and landfill are mostly driven by legislation or markets. Figure 2 shows examples of product attributes comparing a "design as usual" scenario with a "design option A" for a washing machine. The indices $r$ are representative for either component number or mass content of a single washing machine and can be interpreted as a result of design efforts to summarize components to, e.g., functional clusters (modules).

The design as usual scenario (left-hand side) implies that the washing machine is designed for 7 years while the use lifetime is not considered and therefore unknown. Hence, the index for leakage $\left(r_{\text {leakage }}\right)$ is 1 since the entire washing machine $(100 \%)$ leaves the value chain without any reuse, remanufacturing, or recycling activities of the manufacturing company. The leakage index can be interpreted as environmental leakage. Since there is not any control over leaked components, different assumptions can be made. In an optimistic scenario, all leaked components are recycled while in a pessimistic scenario, leaked components are landfilled.

On the other hand, the design option A of the washing machine (right-hand side in Fig. 2) has been designed for two lifecycles with a physical lifetime of 10 years and use lifetime of 5 years for each lifecycle. In order to fulfill this requirement, a designer can redesign the product to incorporate EoL strategies of reuse $\left(r_{\text {reuse }}\right)$, remanufacturing $(r$ remanufacturing $)$, and recycling $\left(r_{\text {recycling }}\right)$ for the washing machine which will result in different numerical values for the design attributes. In doing so, designers can create various design options through redesign of the washing machine which results in different numerical values for design
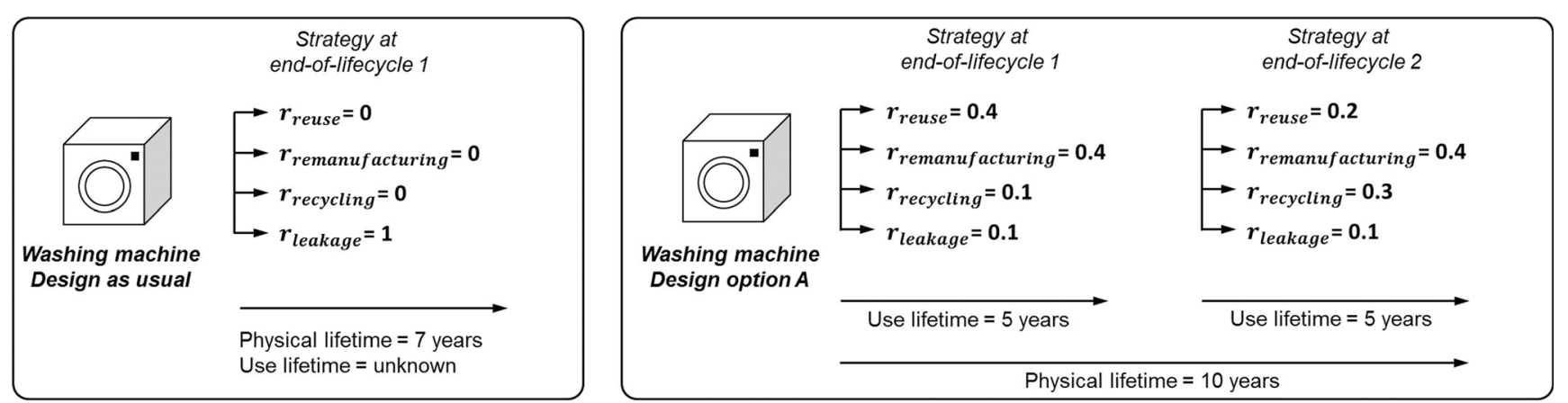

Fig. 2 Examples of product attributes in case of "design as usual" and "design option A" based on [2] 
attributes. For each combination of design indices, the designer can roughly estimate the increase/decrease of cost and $\mathrm{CO}_{2}$ impact in relation to the business as usual case. For the forthcoming work, indices at product level will be broken down to component level to make the indices applicable for a simulation model.

\subsection{Estimation of design efforts for implementing end-of-life strategies}

The EoL strategies are associated with the following efforts and processes on component level:

- Reuse: the component is recovered for next use cycle with minimum effort, i.e., cleaning and visual inspection

- Remanufacturing: the component is recovered for next use cycle with considerable effort, i.e., cleaning, engineering processing (e.g., coating, heat treatment, or testing), and visual inspection

- Recycling: the material is recovered with extensive effort, i.e., cleaning and smelting

Fundamental assumption at this point is that design effort and recovery effort stand in inverse proportion to each other. To be more specific, it is assumed that a designer is required to put more effort in terms of material choices and planning of recovery activities if processes beyond the linear scope are considered, such as "design for disassembly" and "reuse" after the use phase. The least extensive and complex the value recovery at the end of a product's use phase, the higher the designer's effort in terms of foresight and planning at development stage. Thus, the actual design effort at the stage of development is greater when designing for reuse than for remanufacturing. Similarly, designing for remanufacturing requires greater design effort than design for recycling. Figure 3 shows how design effort and design indices are related in the given context.

In order to form a baseline, an existing linear design is presumed associated with design effort $d_{\text {Linear }}$ having a leakage index $r_{\text {leakage }}$ of 1 . Furthermore, it is assumed that design efforts $d$ for each EoL strategy increase exponentially and reach a maximum predefined value $\max d_{R}$ (where $\mathrm{R}$ is any of the three EoL strategies reuse, remanufacturing, or recycling). Design effort $d$ as a result of chosen design indices $r_{R}$ can then be formally expressed as function of the EoL strategies R:

$d(R)=\left(\max d_{R}\right)^{r_{R} *} d_{\text {Linear }}$

Considering only additional design efforts $\Delta d$ for realizing one EoL strategy R in comparison to an existing linear design leads to the expression

$\Delta d(R)=\left(\left(\max d_{R}\right)^{r_{R}-1}\right)^{*} d_{\text {Linear }}$

In order to account for the overall additional design effort $\Delta D$ as a result of various combined efforts $\Delta d$ for different EoL strategies, $\mathrm{R}$ leads to the following formulation:

$\Delta D(R)=\sum_{R=1}^{3} \Delta d(R)$

To give an example, it is assumed that a baseline of $d_{\text {Linear }}$ of 1 exists. If the additionally required design effort for making the entire product reusable after the use phase is presumed to be $30 \%$ of the linear design effort (as a result of a certain degree of complexity of the product properties), then the value of $\max d_{\text {reuse }}$ is 1.3. In the same manner, remanufacturing is assumed to $\max d_{\text {reman }}$ have a value of 1.2 (corresponding to $20 \%$ maximum additional design effort for designing an entire product for remanufacturing). Recycling shall not be considered as an option in this simple example. Now, a designer can
Fig. 3 Relationship of design indices and design effort for reuse, remanufacturing, and recycling

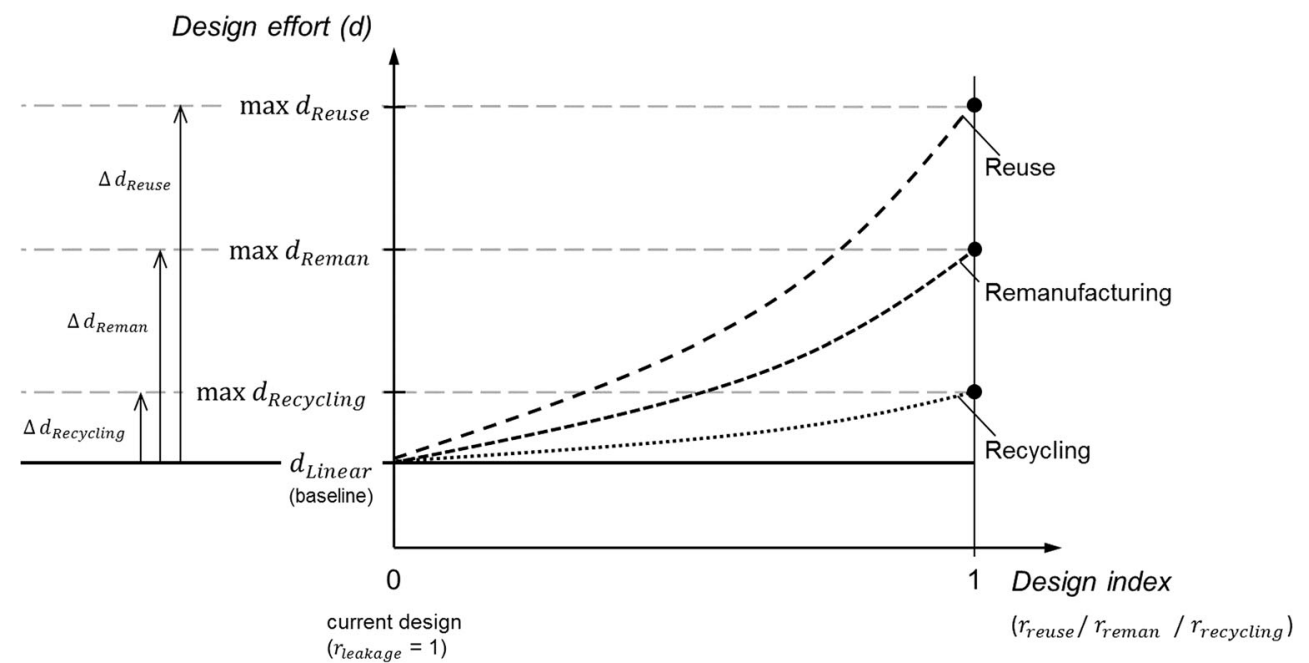


decide to design $50 \%$ of the product for reuse $\left(r_{\text {reuse }}=0.5\right)$ and $30 \%$ for remanufacturing $\left(r_{\text {reman }}=0.3\right)$ while keeping the remaining $20 \%$ as is $\left(r_{\text {recycling }}=0.0\right.$ and $\left.r_{\text {leakage }}=0.2\right)$. Using Eqs. 1 through 3, the additional overall design effort $\Delta D$ results in 0.196 (corresponding to $19.6 \%$ overall additional design effort in comparison to the current linear design).

Based on the shown rationale, designers can define various EoL designs and quantify estimated additional efforts for realizing these designs. In this work, design effort includes all monetary expenses and $\mathrm{CO}_{2}$ emissions up to the point where the component is available in the manufacturing plant and ready for assembly. The forthcoming sections will make use of presented concepts in order to quantify design efforts and design options as input for a simulation model to estimate economic and environmental effects in different business model settings.

\section{Agent-based and discrete event model formulation}

This section describes the design of the $\mathrm{AB}$ component model and the DE model supply chain model. It begins with providing motivation for a multi-method approach. In order to develop a MMM combining $\mathrm{AB}$ and $\mathrm{DE}$ approaches, the models are developed independently and merged afterwards. The method described in Section 3 has been implemented using Anylogic 7.3.4, which is written in Java SE and allows for combining simulation features of $A B$ and DE.

\subsection{Requisite of using a multi-method simulation approach}

Various simulation paradigms are available to date, each one with own advantages and disadvantages. The choice of using a mixed modeling approach is based on the possibility to fulfill two fundamentally different needs.

Firstly, in order to account for in-depth analysis and effects of EoL strategies, individual components need to be mapped in the form of single entities including all their relevant design decisions and data. These entities must be combinable to a new entity to mimic assembly processes in which components form a product and can be disassembled. All components need to be traceable throughout different scenarios. Given the capabilities of $\mathrm{AB}$ approaches to model single entities with individual characteristics including their interactions [28] allows for merging various independent components into a product while maintaining the data on component as well as product level. Hence, each component can be provided with specific data and EoL strategy and made traceable throughout simulation.

Secondly, closed-loop supply chains must adequately reflect CE business operations. This includes operations such as assembly, forward transport, and customer use phase as well as reverse transport in order to account for quality, quantity, and timing of product returns which are considered as one of the critical barriers of CE implementation [29]. DE models contain queuing systems and event triggers which determine the timing of entity movement [30]. In doing so, the focus is put on processes and capacities of systems, which is advantageous when designing supply chain elements including disassembly and reuse, remanufacturing, and recycling activities.

\subsection{Agent-based component model}

The statechart at component level is shown in Fig. 4. In Anylogic, statecharts are used to describe event-driven and time-driven behaviors of agents. Each single component is represented by such a statechart. In Fig. 4, the states are connected with transitions (arrows) to reflect time and state a single component is in as well as the conditions under which that component will transit to another state. A single component can be in four distinct states: manufactured, assembled in product, disassembled after use, material recovered.

The condition under which components may resume the state of assembled in product depends on the chosen EoL strategy, i.e., either reuse or remanufacturing. On the righthand side of Fig. 4, a detailed description regarding all states and transitions in the component agent is provided. Products which consist of $100 \%$ newly manufactured components are called 1st life products and products with a combination of new, reused, and/or remanufactured contents are called $2 n d$ life products.

\subsection{Discrete event supply chain model}

The concept of a circular supply chain model is sketched in Fig. 5. The entire supply chain is divided into three sections: manufacturing and recovery phase, transport phase, use phase.

Starting from the use phase, demand is generated by the arrival of customers over time. The generated demand needs to be met by the modeled manufacturing system consisting of manufacturing, forward and reverse transport, and recovery processes (reuse/remanufacturing/recycling). Using a maketo-order mechanism, the number of products to be produced by the manufacturing system is determined by customer arrivals initiating the assembly process (dotted line in Fig. 4 with the mark "triggers"). In doing so, the assembly process is capable of "pulling" necessary components from two different sources, i.e., either from new components or from inventory of recovered components. In order to account for economic as well as environmental gains of take-back and recovery activities priority in assembly is given to the inventory of recovered components.

After assembly, the product is being delivered via forward transport to the waiting customer where it stays as part of the 


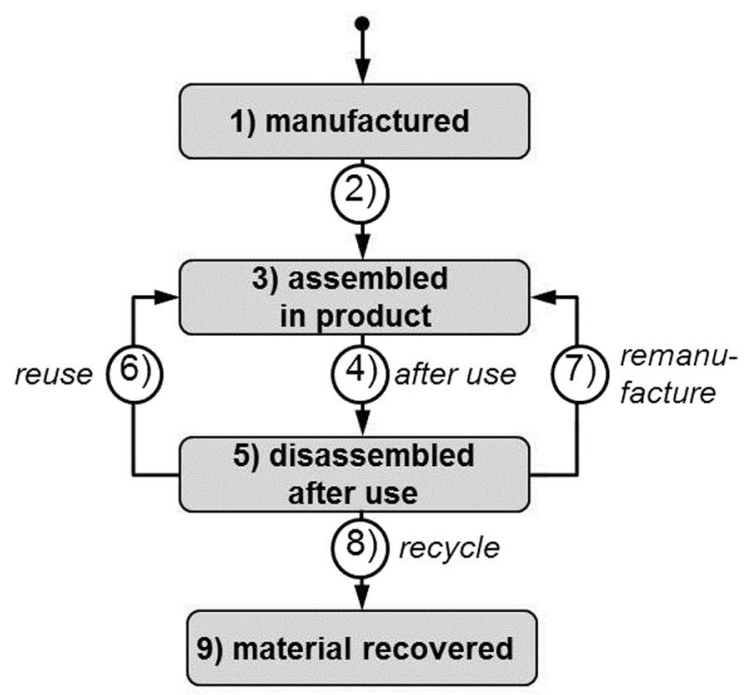

\begin{tabular}{|c|c|c|}
\hline $\begin{array}{l}\text { Number of } \\
\text { element in } \\
\text { statechart }\end{array}$ & $\begin{array}{l}\text { Type of } \\
\text { element }\end{array}$ & Description of actions \\
\hline 1) & $\begin{array}{l}\text { State: } \\
\text { manufactured }\end{array}$ & $\begin{array}{l}\text { - Initialization of single new component including its parameters and } \\
\text { values }\end{array}$ \\
\hline 2) & $\begin{array}{l}\text { Transition: } \\
\text { Condition }\end{array}$ & $\begin{array}{l}\text { - Default value: True (Once manufactured the new component is } \\
\text { directly being sent to assembly state) }\end{array}$ \\
\hline 3) & $\begin{array}{l}\text { State: } \\
\text { assembled }\end{array}$ & $\begin{array}{l}\text { - Component has been sent to assembly line supply chain (DE) } \\
\text { model where it is merged with other components to form a product }\end{array}$ \\
\hline 4) & $\begin{array}{l}\text { Transition: } \\
\text { Message }\end{array}$ & $\begin{array}{l}\text { - If the product does return after use (depending on the business } \\
\text { model) it is disassembled in the supply chain model (DE) and } \\
\text { switches to the disassembled state. } \\
\text { - If the product does not return it cannot be disassembled. In this } \\
\text { case the component is assumed to be lost. Since the company has } \\
\text { no control over such an event the component stays in state } 3 \text { ). }\end{array}$ \\
\hline 5) & $\begin{array}{l}\text { State: } \\
\text { disassembled }\end{array}$ & $\begin{array}{l}\text { - Depending on the EoL strategy the component it is going to be: } \\
\text { - reused } 6 \text { ) } \\
\text { - remanufactured } 7 \text { ) } \\
\text { - recycled } 8 \text { ) }\end{array}$ \\
\hline 6) & $\begin{array}{l}\text { Transition: } \\
\text { Message }\end{array}$ & $\begin{array}{l}\text { - After cleaning and visual check the component is made ready for } \\
\text { assembly and sent to inventory for recovered components. }\end{array}$ \\
\hline 7) & $\begin{array}{l}\text { Transition: } \\
\text { Message }\end{array}$ & $\begin{array}{l}\text { - After cleaning, processing and visual check the component is made } \\
\text { ready for assembly and sent to inventory for recovered } \\
\text { components. }\end{array}$ \\
\hline 8) & $\begin{array}{l}\text { Transition: } \\
\text { Message }\end{array}$ & $\begin{array}{l}\text { - After cleaning the component is sent for recycling for material } \\
\text { recovery. }\end{array}$ \\
\hline 9) & $\begin{array}{l}\text { State: } \\
\text { Material } \\
\text { recovered }\end{array}$ & $\begin{array}{l}\text { - After the component has been sent for recycling the material is } \\
\text { recovered outside the company scope and therefore deleted. }\end{array}$ \\
\hline
\end{tabular}

Fig. 4 Statechart for component agents including descriptions

use phase before it is transported back to the manufacturing company. At this point, it is assumed that not $100 \%$ of products delivered to the market may return depending on the business model that is being tested. This is marked as "product leakage" in the use phase in Fig. 4. In relation to the leakage defined in Section 3, product leakage addresses entire

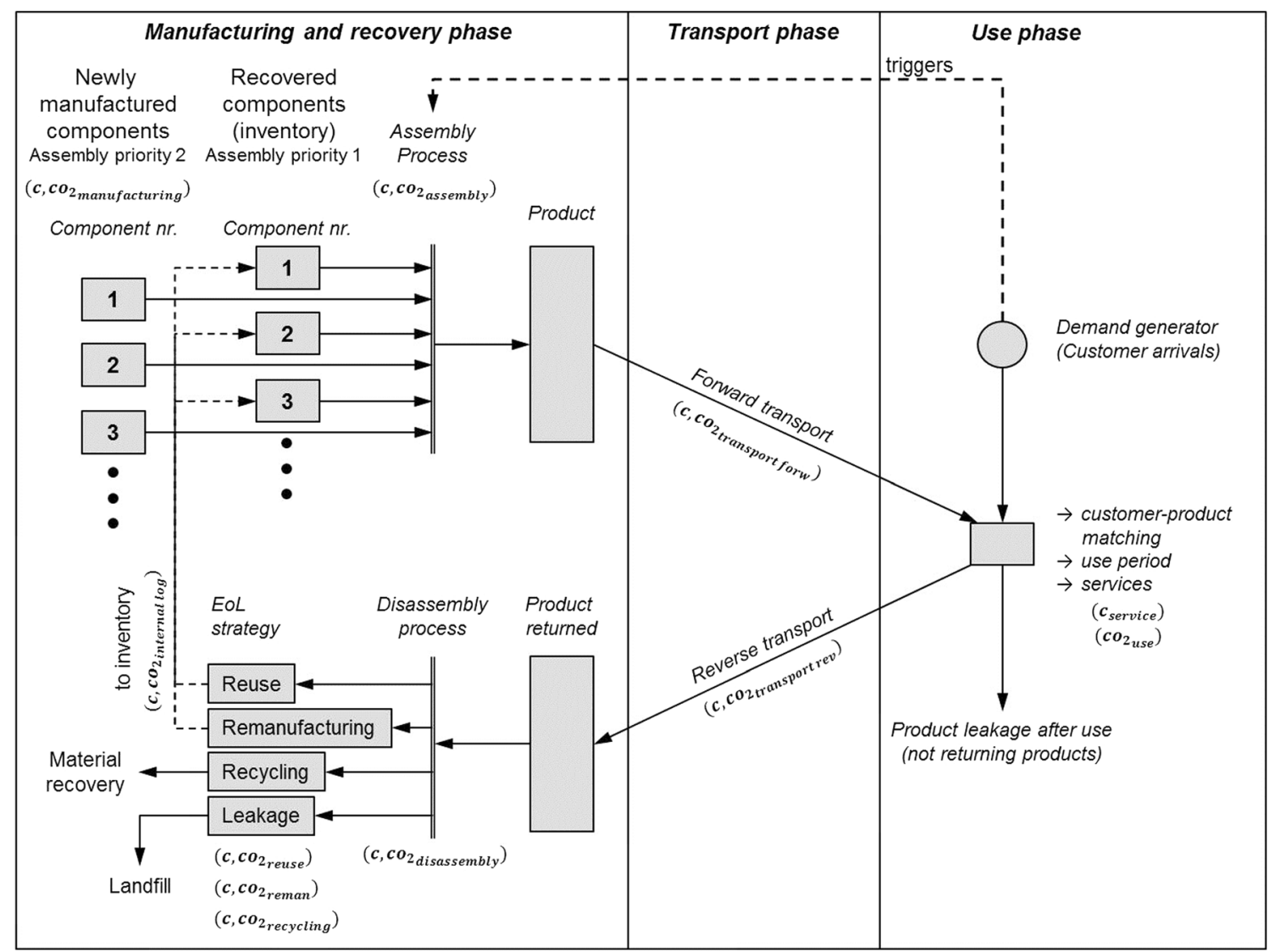

Fig. 5 Circular supply chain process model (arrows stand for movement of components; gray boxes stand for stocks) 
products which do not return to the manufacturer and are lost as part of the business approach. To be more specific, even if buy-back provides customers with an option to sell back the product, it still depends on the customers' motivation to actually do return the product. On the other hand, in pay-per-use or monthly renting, the manufacturer keeps the ownership of the product. As a result, the probability for a product to return is lower in a buy-back model than in a renting or pay-per-use model. Product leakage accounts for this business modelrelated probability of returns.

After return, products are disassembled to component level and processed according to their pre-defined EoL strategy. This means after the processes of reuse and remanufacturing, the components will be delivered to a component inventory to be available for future assembly processes. In the case of recycling, the components are removed from the supply chain since it is assumed that recycled components run through a material recovery process which is not controlled by the manufacturer. If there has not been an EoL strategy assigned to the component, it is treated as environmental leakage (Section 3). Table 1 lists all assumptions used to create the circular supply chain model.

Using the supply chain model, cost $(\mathrm{C})$ and $\mathrm{CO}_{2}\left(\mathrm{CO}_{2}\right)$ estimations per washing machine lifecycle can be made based on aggregated process values using the following formal expressions:

$$
\begin{aligned}
& C_{\text {lifecycle }}=C_{\text {manufacturing }}+C_{\text {assembly }}+C_{\text {transport forw }} \\
& +C_{\text {service }}+C_{\text {transport rev }}+C_{\text {disassembly }}+C_{\text {reuse }}+C_{\text {reman }} \\
& +C_{\text {recycling }}+C_{\text {internal } \log } \\
& \mathrm{CO}_{2_{\text {ijiecycle }}}=\mathrm{CO}_{2_{\text {manuffacturing }}}+\mathrm{CO}_{2_{\text {assembly }}}+\mathrm{CO}_{2_{\text {transport forw }}} \\
& +\mathrm{CO}_{2_{\text {use }}}+\mathrm{CO}_{2_{\text {transport rev }}}+\mathrm{CO}_{2_{\text {disassembly }}}+\mathrm{CO}_{2_{\text {rease }}} \\
& +\mathrm{CO}_{2_{\text {reman }}}+\mathrm{CO}_{2_{\text {recycling }}}+\mathrm{CO}_{2_{\text {internal log }}}
\end{aligned}
$$

The cost and $\mathrm{CO}_{2}$ values of each process step in Eqs. 4 and 5 are mapped to the corresponding supply chain process in Fig. 5.

\subsection{Model integration and implementation}

As a following step to the previous sections, component agents and circular supply chain model need to be integrated. Figure 6 provides an overview how model elements are connected. Starting from the left-hand side, the entire mechanism requires that all component-specific data is available and provided as input as discussed in Section 3. As a supporting tool, MS Excel has been used to capture and structure componentspecific data in the necessary format. For implementation, all necessary data shown on the left-hand side of Fig. 6 has been prepared per component in an Excel spread sheet (one Excel
Table 1 List of assumptions used to develop the circular supply chain model

- For the purpose of modeling closed-loop supply chains, it is assumed that industrial businesses consider (1) providing access to products rather than ownership and (2) taking their products back for the purpose of value recovery.

- Customer arrival rates trigger the assembly process in a make-to-order mechanism. In doing so, components are merged to one product and delivered to the customer without delays.

- For the assembly process, recovered components are prioritized over newly manufactured components. Only if the inventory of recovered components is empty, new components will be manufactured. Reused and remanufactured components are assumed to be in a new-like condition as a result of the value recovery process and additional design efforts considering more than one lifecycle (Section 3.2).

- During the use phase, routine service activities are carried out. The extent of service activities during use phase is dependent on the length of the use phase and the operated business model.

- There is a fraction of products which will not return to the manufacturer from the market (product leakage). This fraction depends on the chosen business model and is an input.

- Returning products are disassembled to component level and then processed according to their EoL strategy. After the final use lifecycle of the components, they can either go to recycling for material recovery or, assuming a pessimistic scenario, go to landfill.

- Cost and $\mathrm{CO}_{2}$ values on product level are broken down to component level based on mass content. For example, a component representing $20 \%$ of the overall product weight accounts for $20 \%$ of the process cost.

row per component). If a specific component is requested during simulation by the supply chain, a component agent is created taking parameter values from the corresponding row in the Excel sheet. In doing so, components that have been initiated in the simulation model are in state 1) manufactured and carry all necessary component data.

The supply chain determines the movement of component agents. At the same time, while passing through the supply chain processes, state changes are prompted on component level. For implementation purposes, message routing rules are applied to connect supply chain events to component transitions. This means once component agents arrive at particular supply chain stocks, messages are sent out to these component agents. These messages then trigger specific transitions within the component agent and thus initiate the change from one state to another. Encircled numbers in the supply chain model on the right-hand side of Fig. 6 indicate which supply chain events are connected to what state changes on component level. To continue the example above, by passing through disassembly process in the supply chain which is marked with 4), the components change their state triggered by the transition with the same number 4).

Another essential feature and advantage of using the $\mathrm{AB}$ approach is the merging of several components to one product. During the assembly process, components are grouped and form collections, i.e., a list of objects. In doing so, multiple component agents are contained in one single unit. As a 
Component information (agent-based)

Circular supply chain setup (discrete event)

Design decisions (input, e.g. Excel)
\begin{tabular}{|l|}
\hline Component number [integer] \\
\hline Component name [string] \\
\hline Material name [string] \\
\hline Component mass $(\mathrm{kg})$ [double] \\
\hline EoL strategy [integer] \\
- Reuse \\
- Remanufacturing \\
- Recycling \\
\hline Cost \& CO2 values ( $€$ \& CO2 kg) [double] \\
- Manufacturing \\
- Assembly \\
- Forward transport \\
- Reverse transport \\
- Disassembly \\
- Reuse (visual check \& cleaning) \\
- Remanufacturing (cleaning \& testing) \\
- Recycling \\
- Internal logistics/handling \\
\hline
\end{tabular}

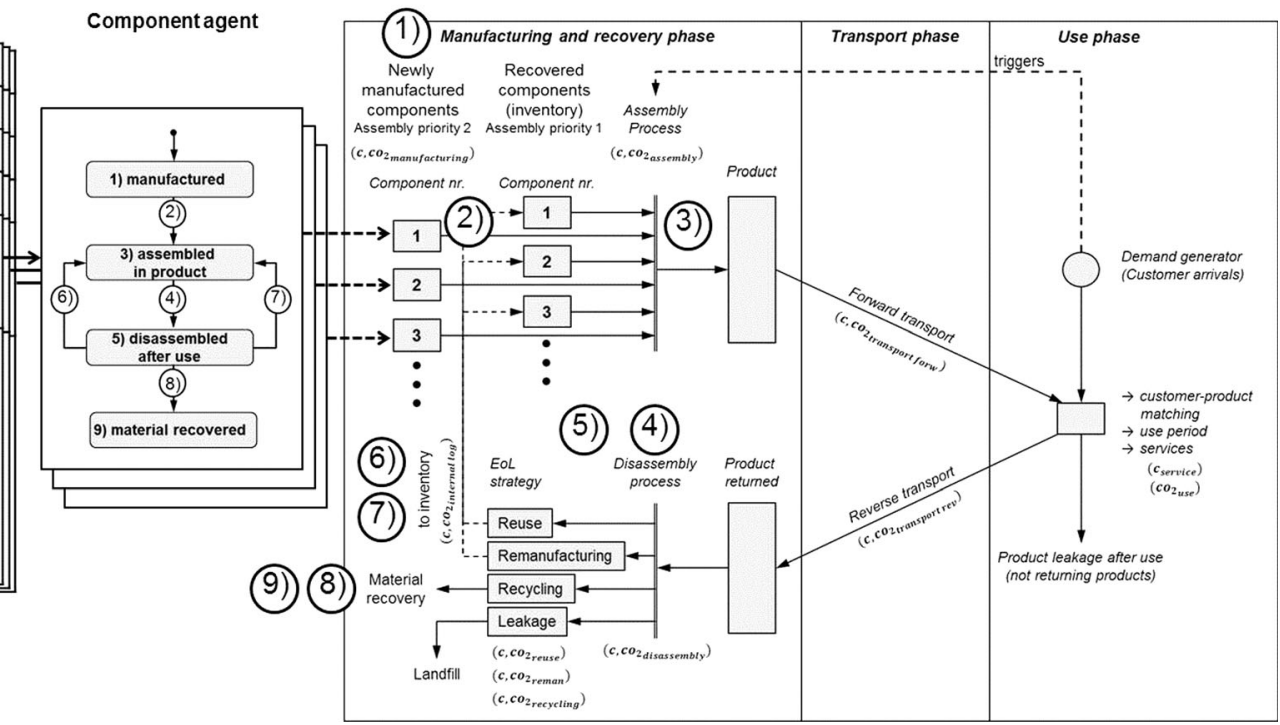

Fig. 6 Overview and connection points of component-specific data, component agent, and circular supply chain

result, one product is capable of storing the data of all components within itself and allows for retrieval of componentspecific information even after disassembly.

\section{Washing machine case}

\subsection{Scenario description}

The simulation time encompasses 15 years in total. Using the example of a washing machine, three distinct design scenarios with different EoL strategies on component level are tested in three different circular business models. As preparatory work for this washing machine case, a fast-track LCA has been performed [31] in order to roughly estimate emissions $\left(\mathrm{CO}_{2}\right)$ of the supply chain sections. As a consequence, the resulting LCA data may not be accurate but provides sufficient information for simulation testing purposes. The cost values on washing machine level have been assumed based on a random supply chain scenario in order to obtain preliminary data. Component names, material names, and cost values are based on a real case but have been altered to avoid sensitive information but still keeping a representative case. Direct cost and $\mathrm{CO}_{2}$ values are considered while fixed cost is not considered within the scope of the simulation. The business models that are tested consist of buy-back, leasing, and pay-per-use. There are further suitable business models that could be tested at this point particularly from service orientation point of view. However, for demonstrating purposes of the developed model, these three business models are chosen in the following experiments as they will be associated with different degrees of service.

\subsection{Strategic EoL design scenarios}

Table 2 provides an overview of relevant design options for the simulation runs. Each design option considers all four EoL strategies to different extents based on the number of components. In order to simplify the case and avoid unnecessary details such as single screws and bolts, all washing machine components have been summarized as a total of 33 components for this simulation experiment. Since the indices for environmental leakage are zero, all products run through the recycling process after either first life or after having been reused/remanufactured.

It should be noted at this point that these indices are planned values decided by the designer. Actual values of reused/remanufactured/recycled content per washing machine depend on the business model and the product return rate. To give an example, with business model settings of a pay-peruse approach, planned and actual values will more likely to be equal compared to the business model settings of a buy-back approach. This deviation of planned and actual values is not accounted for in the presented model.

\subsection{Circular supply chain scenarios}

Table 4 provides an overview of main variables, initial values of the main variables, sources, and their units of measure for one washing machine in different supply chain sections. It should be noted at this point that the supply chain variables in Table 4 are associated with one entire washing machine. Even though recycling activities are not part of the circular supply chain in this case, they are considered to full extent from the design point of view. In doing so, implications of 
Table 2 Washing machine design options considering different EoL strategies (based on number of components)

\begin{tabular}{llll}
\hline EoL strategy $^{\mathrm{a}}$ & Design option 1 & Design option 2 & Design option 3 \\
\hline Reuse $\left(r_{\text {reuse }}\right)$ & 0.70 & 0.48 & 0.24 \\
Remanufacturing $\left(r_{\text {reman }}\right)$ & 0.24 & 0.39 & 0.58 \\
Recycling $\left(r_{\text {recycling }}\right)$ & 0.06 & 0.12 & 0.18 \\
Environmental leakage $\left(r_{\text {leakage }}\right)$ & 0.00 & 0.00 & 0.00 \\
\hline
\end{tabular}

${ }^{\text {a }}$ Based on the rationale described in Section 3.2, the following values have been chosen for maximum design effort: $\max d_{\text {reuse }}=1.3(+30 \%) ; \max d_{\text {reman }}=1.2(+20 \%) ; \max d_{\text {recycling }}=1.05(+5 \%)$ design decisions are taken into account regarding treatment after a product's physical lifetime. Regardless of the fact that recycling can be performed by the manufacturing company or a third party, designers ensure that the product is designed in a way that it eliminates the idea of landfilling.

For the three business models buy-back, leasing, and payper-use, different assumptions are made which result in different parameter settings of the circular supply chain. The buyback offer includes a buy-back option in which customers have the opportunity to sell the washing machine back to the manufacturer. With respect to the possibility that a customer might not return washing machines despite the buy-back option (due to, e.g., convenience of not returning or preference of ownership), it is assumed that the return rate is lower compared to the leasing and the pay-per-use offer. The leasing and pay-per-use offer are service-oriented offers in which customers receive a washing machine including installation at home. In the leasing model, the customer pays for having access to a washing machine for a defined period of time, e.g., per month. The pay-per-use model charges per actual use cycle, i.e., in the case of a washing machine, customers pay per actual washing cycling. While the focus of the leasing model is to provide availability, the pay-per-use model focuses on providing the function of "cleaning clothes". Often, additional service offers are associated with the pay-per-use model compared to the leasing model, such as provision of detergent. As a result, the connection between customers and manufacturer is assumed to be closest in the pay-per-use model. In both of the models leasing and pay-per-use, the manufacturer retains the ownership of the product. Based on the given business scenarios, the quality, quantity, and timing of product returns will differ. Table 3 lists all assumptions used to create the simulation model.

For each of the design options in Table 4, different manufacturing costs are associated since it is assumed that improving the design for recovery purposes will result in additional efforts. Taking the linear design as baseline, the additional effort to design an entire washing machine for reusability is associated with largest expenses and multiplied with a factor of $1.3(+30 \%)$. The effort to design an entire washing machine for remanufacturing is assumed with additional expenses of $20 \%$, and for recycling of $5 \% . \mathrm{CO}_{2}$ manufacturing values are treated in the same manner. A full list of assumed cost shares and $\mathrm{CO}_{2}$ values for all components and supply chain sections can be found in the Appendix.

\section{Simulation results}

Ten distinct simulation runs have been performed. At first, three different design options are explored in combination with three different business models. This explorative study will be helpful in identifying the most effective business settings provided different design options. As a second step, the most effective business setting is selected and fixed to create constraints for an optimization experiment. In this optimization study, the cost minimum EoL strategies on component level are identified given a predefined amount of allowed additional effort for design. As the components pass through the supply chain, cost and emission values are logged, saved, and aggregated. The simulation runs are analyzed and compared to the linear case using the criteria number of customers served per washing machine, overall cost, and $\mathrm{CO}_{2}$ emissions. The baseline is formed by a linear scenario where washing machines are manufactured and transported to the customer without the possibility of take-back. The use phase in the linear setting has been assumed with 7 years and associated

Table 3 List of assumptions used to develop the strategic business scenario

- The quality of product returns and hence the success rate of reuse and remanufacturing operations are at a level of $100 \%$ since the design ex ante considers product returns and recovery. This is an implication and consequence of additional design efforts which have been discussed in Section 3.2.

- The quantity of products that return from the market (product return rate) is higher the more service oriented the business model. This is based on the assumption that the manufacturer has higher involvement with the customer and gains more control over the product during the use phase as more service elements are offered.

- The timing of returns is uncertain. However, there are different degrees of uncertainty depending on the selected business model. The more service oriented the chosen business model, the lower the uncertainty in terms of timing. This has been accommodated in the model by using different normal distributions for the end of the use phase (see Table 4). 
Table 4 Main variables, initial values of the main variables, and their units of measure for one washing machine on supply chain level

\begin{tabular}{|c|c|c|c|c|c|c|}
\hline \multicolumn{2}{|l|}{ Main supply chain variables } & Buy-back & Leasing & Pay-per-use & $\begin{array}{l}\text { Unit of } \\
\text { measure }\end{array}$ & Source \\
\hline \multicolumn{7}{|l|}{ Use phase } \\
\hline \multirow{2}{*}{\multicolumn{2}{|c|}{ End of use phase }} & Normal distribution & Normal distribution & Normal distribution & Years & Assumed \\
\hline & & $\mu=4 . \quad=1.2$ & $\mu=4 . \sigma=0.5$ & $\mu=4 . \sigma=0.3$ & & \\
\hline \multicolumn{2}{|l|}{ Product return rate } & 0.6 & 0.8 & 0.95 & Percent & Assumed \\
\hline \multicolumn{2}{|l|}{$\begin{array}{l}\text { Frequency of routine servicing } \\
\text { activities during use phase }\end{array}$} & 0.25 & 1.25 & 2 & 1/year & Assumed \\
\hline \multirow{2}{*}{$\begin{array}{l}\text { Average cost of one servicing } \\
\text { visit at customer site } \\
\text { (includes transport and frequently } \\
\text { replaced service parts) }\end{array}$} & Cost & \multicolumn{3}{|c|}{40.00} & Euro & Assumed \\
\hline & $\mathrm{CO}_{2}$ & \multicolumn{3}{|c|}{$\begin{array}{c}0.69 \\
\text { (forward and reverse transport) }\end{array}$} & $\mathrm{CO}_{2} \mathrm{~kg}$ & LCA \\
\hline \multicolumn{2}{|l|}{$\mathrm{CO}_{2}$ emissions during use phase } & \multicolumn{3}{|c|}{$\begin{array}{c}5088 \\
\text { (based on linear scenario: } 13,000 \mathrm{CO}_{2} \mathrm{~kg} \text { for } 7 \text { years) }\end{array}$} & $\mathrm{CO}_{2} \mathrm{~kg} /$ day & LCA \\
\hline \multicolumn{2}{|l|}{ Customer demand } & \multicolumn{3}{|c|}{$\begin{array}{c}1000 \\
\text { (exponential distribution: } \lambda=1000)\end{array}$} & 1/year & Assumed \\
\hline \multicolumn{7}{|c|}{ Manufacturing and recovery phase } \\
\hline \multicolumn{2}{|c|}{$\begin{array}{l}\text { Total number of components in } \\
\text { washing machine (simplified) }\end{array}$} & \multicolumn{3}{|c|}{33} & $\begin{array}{l}\text { Components } \\
\text { per WM }\end{array}$ & LCA \\
\hline \multirow{2}{*}{$\begin{array}{l}\text { Manufacturing } \\
\text { design option } 1 \\
(\Delta D:+24.9 \%)^{a}\end{array}$} & Cost & \multicolumn{3}{|c|}{707.29} & Euro & Assumed \\
\hline & $\mathrm{CO}_{2}$ & \multicolumn{3}{|c|}{6618.63} & $\mathrm{CO}_{2} \mathrm{~kg}$ & LCA \\
\hline \multirow{2}{*}{$\begin{array}{l}\text { Manufacturing } \\
\text { design option } 2 \\
(\Delta D:+21.6 \%)^{a}\end{array}$} & Cost & \multicolumn{3}{|c|}{688.75} & Euro & Assumed \\
\hline & $\mathrm{CO}_{2}$ & \multicolumn{3}{|c|}{6445.06} & $\mathrm{CO}_{2} \mathrm{~kg}$ & LCA \\
\hline \multirow{2}{*}{$\begin{array}{l}\text { Manufacturing } \\
\text { design option } 3 \\
(\Delta D:+18.53 \%)^{\mathrm{a}}\end{array}$} & Cost & \multicolumn{3}{|c|}{671.31} & Euro & Assumed \\
\hline & $\mathrm{CO}_{2}$ & \multicolumn{3}{|c|}{6281.88} & $\mathrm{CO}_{2} \mathrm{~kg}$ & LCA \\
\hline \multirow{2}{*}{ Assembly } & Cost & \multicolumn{3}{|c|}{20} & Euro & Assumed \\
\hline & $\mathrm{CO}_{2}$ & \multicolumn{3}{|c|}{32} & $\mathrm{CO}_{2} \mathrm{~kg}$ & LCA \\
\hline \multirow{2}{*}{ Disassembly } & Cost & & 50.00 & & Euro & Assumed \\
\hline & $\mathrm{CO}_{2}$ & & 200 & & $\mathrm{CO}_{2} \mathrm{~kg}$ & LCA \\
\hline Reuse & Cost & & 150.00 & & Euro & Assumed \\
\hline Reuse & $\mathrm{CO}_{2}$ & & 1133 & & $\mathrm{CO}_{2} \mathrm{~kg}$ & LCA \\
\hline & Cost & & 200.00 & & Euro & Assumed \\
\hline Remanutacturıng & $\mathrm{CO}_{2}$ & & 1400 & & $\mathrm{CO}_{2} \mathrm{~kg}$ & LCA \\
\hline & Cost & & 350.00 & & Euro & Assumed \\
\hline Recycling & $\mathrm{CO}_{2}$ & & 5215 & & $\mathrm{CO}_{2} \mathrm{~kg}$ & LCA \\
\hline & Cost & & 1.25 & & Euro & Assumed \\
\hline Internal logistıcs & $\mathrm{CO}_{2}$ & & 0.1 & & $\mathrm{CO}_{2} \mathrm{~kg}$ & LCA \\
\hline Transport phase & & & & & & \\
\hline & Cost & & 2.50 & & Euro & Assumed \\
\hline Forward transport & $\mathrm{CO}_{2}$ & & 0.23 & & $\mathrm{CO}_{2} \mathrm{~kg}$ & LCA \\
\hline & Cost & & 5.00 & & Euro & Assumed \\
\hline Reverse transport & $\mathrm{CO}_{2}$ & & 0.46 & & $\mathrm{CO}_{2} \mathrm{~kg}$ & LCA \\
\hline
\end{tabular}

${ }^{\mathrm{a}}$ Based on the rationale described in Section 3.2, $\Delta D$ has been calculated for each design option using the following values: $d_{\text {Linear }}=1 ;$ max $d_{\text {reuse }}=1.3$; $\max d_{\text {reman }}=1.2 ; \max d_{\text {recycling }}=1.05$. As linear baseline scenario, manufacturing cost of 566.38 euros and $5300 \mathrm{CO}_{2} \mathrm{~kg}$ have been assumed per washing machine 
Number of customers served per washing machine

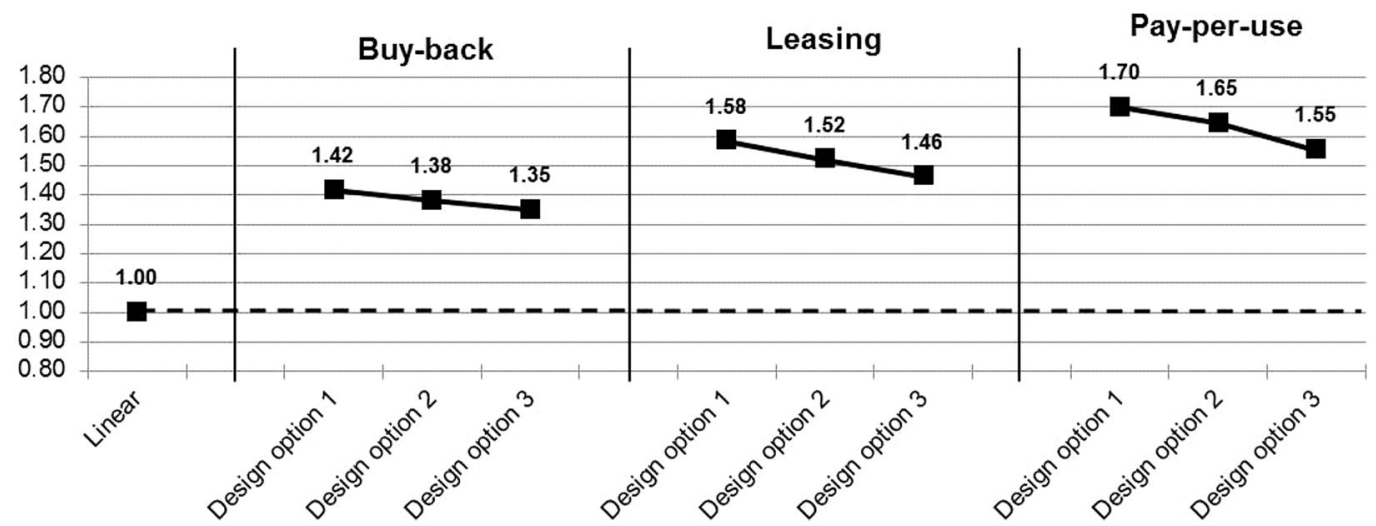

Aggregated lifecycle cost (in Euro)

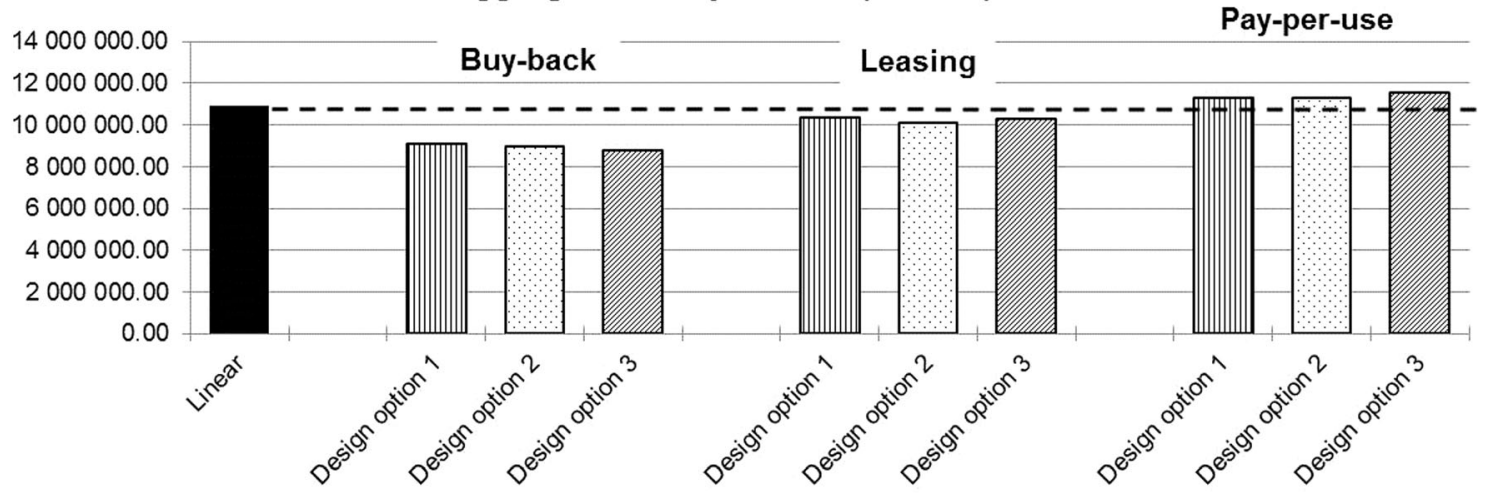

Aggregated lifecycle impact (in $\mathrm{CO} \mathbf{~ k g )}$

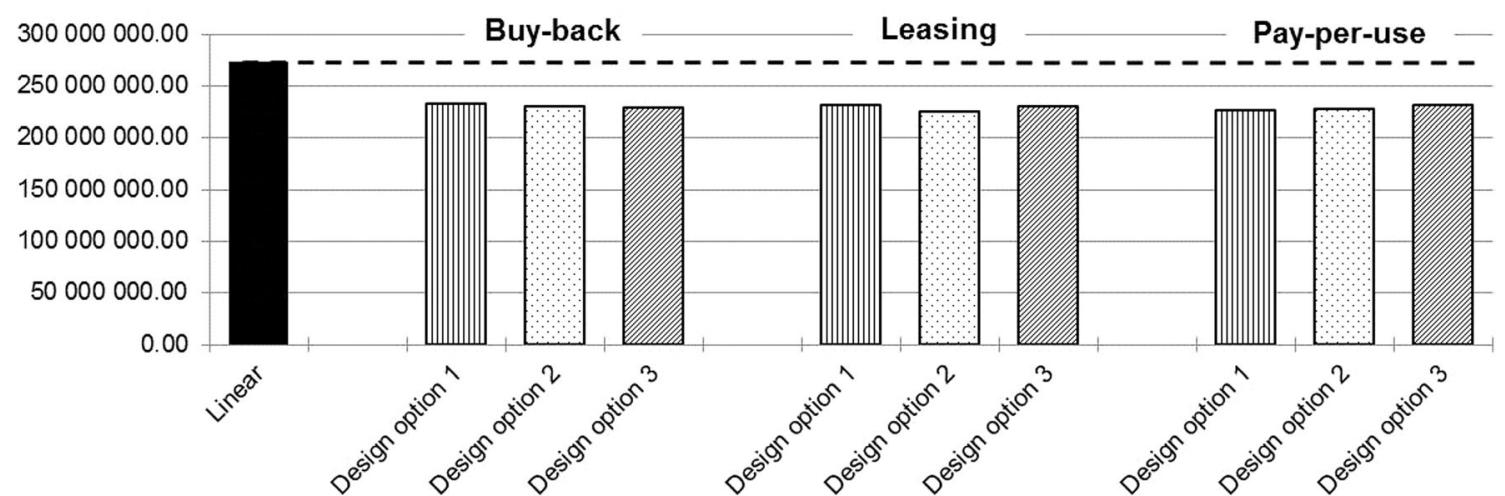

Fig. 7 Number of customers served per washing machine, aggregated lifecycle cost, and impact for distinct three design options and three supply chains in a 15 -year scenario

with the $\mathrm{CO}_{2}$ values of the forward supply chain, however, without any service activities.

\subsection{Exploration of circular design strategies and business scenarios}

Figure 7 shows the number of customers served per washing machine as well as aggregated lifecycle cost and impact of each design option in each of the circular supply chain scenarios.
Comparing the three business scenarios in general, it can be stated that the more service oriented the business and supply chain setting, the more costly the business operations. While the buy-back and the leasing model are less cost intensive than the linear model, the payper-use model exceeds the linear setting with all of the three design options. This can be explained through increased expenses for service and transports during customer use phases which are greater compared to other scenarios. 
On the other hand, the pay-per-use model serves more customers with a lower number of components. The number of customers per washing machine is highest for design option 1 in the pay-per-use model, i.e., 1.70. this means that in the time period of 15 years on average, 1.70 customers have been served with the components of one single washing machine. The number of customers served per washing machine is highest for design option 1 in all three business model configurations. This is due to the fact that in design option 1 , the largest number of components $(70 \%)$ is planned to be reused and remanufactured compared to the other two design options. Furthermore, the pay-per-use model has the most reliable time-to-recovery since timing and quantity of product returns are less uncertain, i.e., more predictable. This leads to a more steady reverse flow of components to be reused and remanufactured. As a result of both, larger share of components to be reused and remanufactured as well as more steady reverse flows, more components circulate through the closedloop supply chain system and are made available for reassembly to serve new demand streams. Under these circumstances, more frequent transportation occurs which has a strong impact on cost in this supply chain setting.

Results for the $\mathrm{CO}_{2}$ emissions are rather similar for all combinations of design options and business models. Since the use phase has the highest $\mathrm{CO}_{2}$ intensity compared to the other lifecycle phases of the washing machine (see Table 4), the reduction from 7 years in the linear scenario to roughly 4 years in any of the three alternative business models lowers the overall $\mathrm{CO}_{2}$ emissions significantly. The increase of forward and reverse transport of all three alternative business models seems to be overcompensated by $\mathrm{CO}_{2}$ savings resulting from the shortened use phases. This is in line with the input values presented in Table 4.

\subsection{Optimization of circular design strategies in a pay-per-use setting}

Given the previous results, the pay-per-use model in combination with design option 1 seems to deliver the most resource productive result since the largest number of customers can be served per washing machine. In addition, the same business setting performs environmentally better than the linear setting in terms of $\mathrm{CO}_{2}$ emissions. However, from an aggregated lifecycle cost perspective, design option 1 in a pay-per-use model costs roughly 0.3 million euros more than the linear scenario. Hence, in the next step, the pay-per-use supply chain setting based on Fig. 5 provides the basis for an optimization experiment with the aim to make pay-per-use economically more attractive.

The objective is to minimize the aggregated lifecycle cost under variation of different EoL strategies on component level while keeping the pay-per-use supply chain setting (Table 4). For the optimization experiment, the OptQuest simulation optimization engine has been used [32]. The optimization engine runs numerous simulation experiments while varying EoL strategies on component level, thus changing design indices $r$ from simulation run to simulation run to find the optimal (cost minimum) constellation in the pay-per-use setting. Two thousand consecutive simulation runs are performed, which takes roughly 9 hours with a $2.40-\mathrm{GHz}$ Intel Core processor.

The constraints for the optimization experiment are as follows:

- Each component must have one EoL strategy, i.e., either reuse, remanufacturing, or recycling. Leakage is not available as design option for any component.

- The overall additional design effort $\Delta D$ as a result of the chosen EoL constellation may not be greater than for design option 1 which is $0.249(+24.9 \%)$.

At the end of each of the 2000 runs, the overall additional design effort $\Delta D$ of the respective EoL strategy is compared to the value of 0.249 . Simulation outcomes with a lower or equal value than 0.249 are marked as feasible while outcomes with a greater value than 0.249 are marked as infeasible. Figure 8 illustrates the results of the entire optimization experiment of 2000 runs.

As shown in Fig. 8, randomly starting in the range of 10.2 million euros, the EoL strategies of the 33 components could be optimized finally settling around 9.76 million euros. The best feasible solution has been achieved with the design of $0.58,0.39$, and 0.03 for the product design indices $r_{\text {reuse }}, r$ reman, and $r_{\text {recycling, respectively, keeping an overall additional }}$ design effort of 0.2391 . This means that while maintaining business processes of a pay-per-use model with the according supply chain values from Table 4, these design indices indicate the best EoL design strategy that should be adopted from the beginning in order to fulfill business objectives at a minimum cost.

In comparison to design option 1 where the design indices for reuse and remanufacturing combined make up for 0.94 ( $94 \%$ of all components), the optimized result proposes an increase to 0.97 ( $97 \%$ of all components). It is worthwhile to note that the reuse index is reduced from 0.70 to 0.58 while the remanufacturing index has increased from 0.24 to 0.39 . This change towards more remanufacturing can be explained with the constraint on overall design effort. By reducing the design index for reuse, the potentially available design effort is increased, which can be used for any of the other two design strategies remanufacturing and recycling. As also shown in Fig. 3, the strategies remanufacturing and recycling require less design effort than the strategy of reuse. As a result, the remanufacturing index increases since more components can be circulated maintaining the same level of overall design effort.

The best infeasible solution is the solution with maximum overall design effort to design a washing machine for $100 \%$ 
Fig. 8 Results of cost optimization experiment for payper-use model (2000 consecutive simulation runs, 15-year scenario)

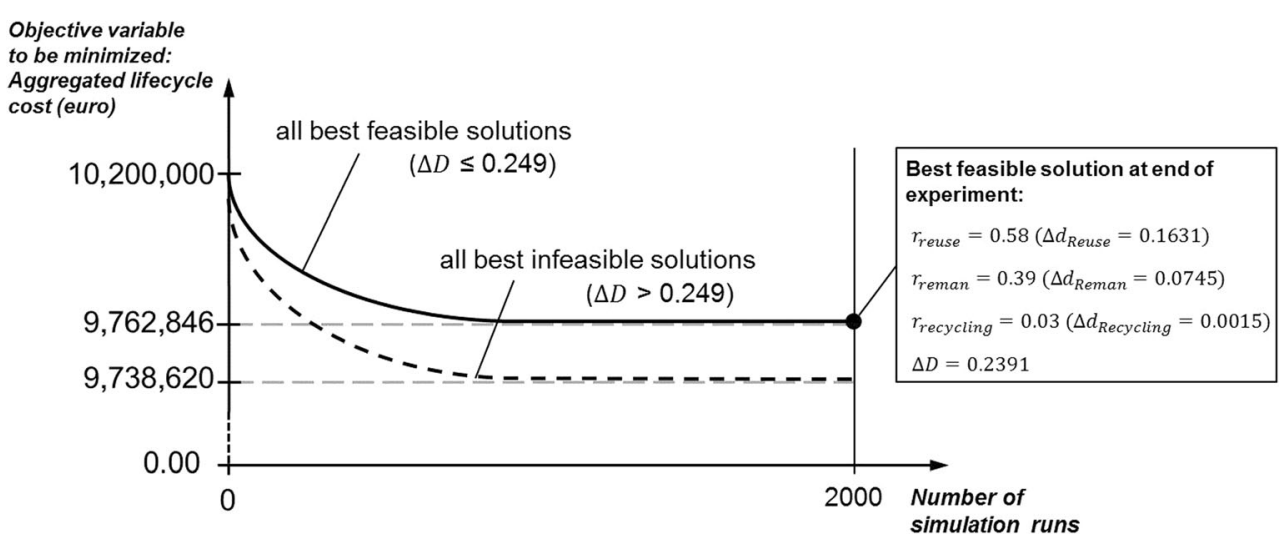

reuse. Based on the input from Table $4, \Delta D$ can reach a maximum value of 0.3 (since $\max d_{\text {reuse }}=1.3$ ). At this point, tradeoffs between increases of design efforts and resulting potential cost savings can be identified.

Thus, it can be concluded that through variation of EoL strategies in a given pay-per-use setting and a maximum additional design effort of $24.9 \%$, economic savings of roughly 1.1 million euros (equivalent to $-10.4 \%$ ) could be realized (comparing the best feasible result of 9,762,846 million euros in Fig. 8 with $10,892,909$ million euros in the pay-per-use setting for design option 1 in Fig. 7). With this EoL strategy, the aggregated lifecycle cost can be reduced to a level below all of the three leasing models (Fig. 7) while still fulfilling the business objectives of a pay-per-use model. Table 5 gives an overview of the associated EoL strategy for each component including a comparison to the design option 1. It is worthwhile to note how the design strategy as achieved after optimization differs from the initial design option. Fourteen out of 33 components $(42 \%)$ have changed their EoL strategy while the other 19 components have remained as assigned by design option 1.

As second level results using $\mathrm{AB}$ approach on component level, component-specific data can be extracted. Figure 9 shows aggregated lifecycle cost where cost per component number has been extracted and summed up for the duration of 15 years. Component lifecycle cost is compared for the cases linear, design option 1, and optimized pay-per-use design.

Compared to the linear scenario, each component with the EoL strategy reuse experiences a cost reduction of $28.49 \%$ when pursuing the optimized design strategy. For each component with the EoL strategy remanufacturing, this cost reduction is $25.47 \%$. On the other hand, component number 6 with the EoL strategy recycling is penalized with a cost increase of $36.08 \%$. It seems at this point that the optimized design strategy is advocating a case against recycling in relation to reuse and remanufacturing as these two strategies are connected to economic savings.
In the supply chain model (Fig. 5), components leave the closed-loop system without the possibility of being reassembled. In this scenario, the relative cost increase for recycled components can be interpreted as cost of regulatory measures, which requires original equipment manufacturers to be responsible for their EoL products in order to avoid landfilling. Typical examples are EU's End-of-Life-Vehicle directive (ELV Directive) from 2000 and The Waste Electrical and Electronic Equipment Directive (WEEE Directive) from 2002. Thus, the relative cost increase for recycled components might compensate for regulatory cost at EoL of components.

Furthermore, in order to analyze environmental benefits, component mass and material information have been extracted from the component agents. These data sets have then been compared for the optimized design and the linear scenario. Figure 10 provides an overview about the saved mass of washing machine materials in the optimized design for the pay-per-use case. Roughly 326 tons of material could be saved in 15 years for a given number of customers served. This information is useful when it comes to making design decisions in the light of resource scarcity and material criticality.

\subsection{Discussion}

This research introduces the first MMM to quantify and study the outcomes of different EoL strategies on component level in different circular business model settings. In relation to the simulation results, it appears that an initially more costly payper-use model can be made economically more attractive and thus practically more feasible by optimizing EoL strategies on component level. The optimization experiment indicates that economic potentials can be identified as well as trade-offs between design efforts and cost performance quantified.

In this work, the pay-per-use model has been chosen for optimization. This has been based on the scenario that a company follows the policy of resource conservation and therefore aims at maximizing the number of customer served with as little resources as possible. In a case where the washing 
Table 5 Overview of EoL strategies for 33 components for design option 1 and optimized pay-per-use design

\begin{tabular}{|c|c|c|c|c|}
\hline Component number & Material name & $\begin{array}{l}\text { Manufacturing cost } \\
\text { (euro), } \Delta D=0.249\end{array}$ & $\begin{array}{l}\text { Design option } 1 \\
\text { (before optimization), } \\
\Delta D=0.249\end{array}$ & $\begin{array}{l}\text { Optimized pay-per-use } \\
\text { design (after optimization) } \\
\Delta D=0.2391\end{array}$ \\
\hline 1 & Material A & 12.76 & Reuse & Reuse \\
\hline 2 & Material B & 1.53 & Reuse & Reuse \\
\hline 3 & Material C & 2.77 & Reuse & Reuse \\
\hline 4 & Material D & 4.16 & Reuse & Reuse \\
\hline 5 & Material D & 13.87 & Reuse & Reuse \\
\hline 6 & Material B & 1.39 & Reuse & Recycle \\
\hline 7 & Material C & 27.75 & Reuse & Reuse \\
\hline 8 & Material E & 74.79 & Reuse & Reuse \\
\hline 9 & Material F & 69.37 & Reuse & Reuse \\
\hline 10 & Material B & 0.69 & Reuse & Reuse \\
\hline 11 & Material B & 0.28 & Reuse & Reuse \\
\hline 12 & Material B & 8.05 & Reuse & Reman \\
\hline 13 & Material G & 5.55 & Reman & Reman \\
\hline 14 & Material B & 1.39 & Recycle & Reuse \\
\hline 15 & Material G & 1.25 & Reman & Reuse \\
\hline 16 & Material B & 6.10 & Reuse & Reman \\
\hline 17 & Material A & 6.94 & Recycle & Reuse \\
\hline 18 & Material H & 3.33 & Reman & Reman \\
\hline 19 & Material I & 17.76 & Reman & Reuse \\
\hline 20 & Material J & 52.72 & Reman & Reman \\
\hline 21 & Material J & 55.50 & Reuse & Reuse \\
\hline 22 & Material J & 35.52 & Reuse & Reuse \\
\hline 23 & Material A & 20.95 & Reuse & Reman \\
\hline 24 & Material A & 11.10 & Reuse & Reman \\
\hline 25 & Material A & 5.55 & Reuse & Reman \\
\hline 26 & Material A & 15.26 & Reuse & Reman \\
\hline 27 & Material A & 6.94 & Reuse & Reuse \\
\hline 28 & Material K & 4.16 & Reuse & Reman \\
\hline 29 & Material L & 0.69 & Reuse & Reman \\
\hline 30 & Material M & 6.94 & Reuse & Reuse \\
\hline 31 & Material M & 88.80 & Reman & Reuse \\
\hline 32 & Material H & 41.62 & Reman & Reman \\
\hline 33 & Material M & 83.25 & Reman & Reman \\
\hline
\end{tabular}

machine contains a larger number of scarce materials, the choice of the pay-per-use model seems strategically most beneficial since the return rate is higher and more stable compared to the other models. On the other hand, the pay-per-use model is the most expensive choice with regard to loop closure due to high operational cost. Thus, if a company hypothetically prioritizes reduction of lifecycle cost while using abundant materials, then the buy-back model might be the more beneficial choice. However, in the case of buy-back, the uncertainty and risk of quantity and timing is greater as assumed in Table 4. Based on this discussion, the utility of the presented tool can be demonstrated as strategic support for decision-making through systematic quantification, exploration, and optimization of different business scenarios.

As shown by the washing machine example, the estimation of overall cost and $\mathrm{CO}_{2}$ emissions under consideration of quality, quantity, and timing of returns becomes practically challenging with larger numbers of components. The presented approach can be supportive of reducing the practical challenges arising from increasing amount of critical factors which need to be considered simultaneously in circular manufacturing systems. 


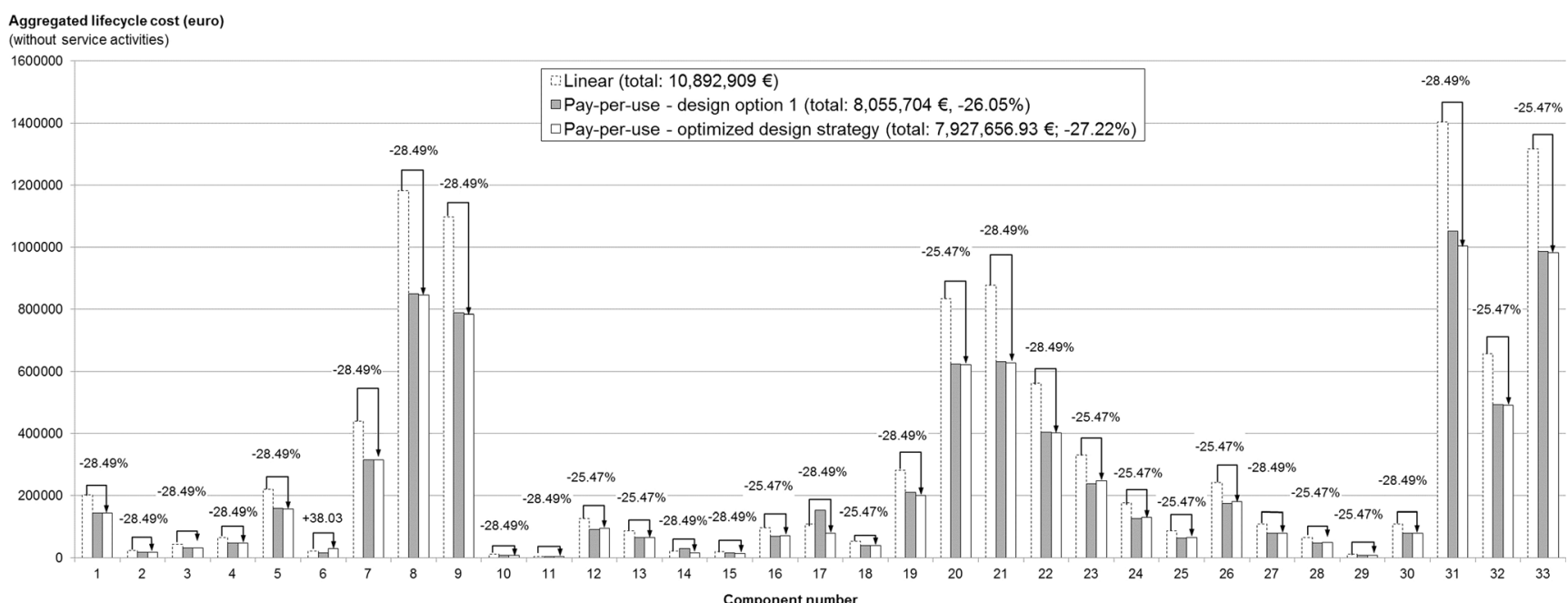

Fig. 9 Comparison of aggregated lifecycle cost for 33 washing machine components in a 15-year scenario (cases: linear, design option 1, optimized payper-use design)

At this point the boundary of the model needs to be questioned. The presented approach solely considers direct cost associated with components. It does not consider fixed cost or investment needed in order to set up the required circular infrastructure in terms of reverse logistics and recovery facilities. However, based on existing designs, decisionmakers can create reasonable scenarios about their planned efforts and the structure of their products. The obtained results from this analysis tool can then serve as a basis in the form of a steady-state result of a circular manufacturing system. This facilitates identification of suitable pay-off periods for investments to implement necessary infrastructure. Major strength of the presented approach is the breakdown to operational level. The achieved level of detail in combination with simulation techniques capable of pressing several years into a few minutes significantly reduces uncertainty at early design stage.

It needs to be mentioned that the assumption of constant customer demand in the light of business model changes is not realistic. It can and should be expected that customer demand will not remain constant when changing the business model from conventional sales to, e.g., pay-per-use. However, as the scope of the paper is to support decision-makers from a company-internal design and business perspective and not from a customer acceptance perspective, the given results are representative of the scope of the problem. One of the following steps is to expand the simulation model and include varying demand profiles as well as revenue streams.

As a modeling approach, the combination of $\mathrm{AB}$ and $\mathrm{DE}$ seems highly beneficial in connecting design and business strategy. Different levels of detail can be considered in one single approach. Design decisions and data sets on component level can be saved and accessed at any stage in the supply chain. Cost and $\mathrm{CO}_{2}$ effects over time can be aggregated and made assessable in various DE supply chain models. Since in practice industrial businesses are well aware about cost values and increasingly also about their environmental impact, the resulting quantitative information provides decision-makers
Fig. 10 Material savings in kilograms comparing optimized design to linear scenario
Material savings (mass, $\mathrm{kg}$ )

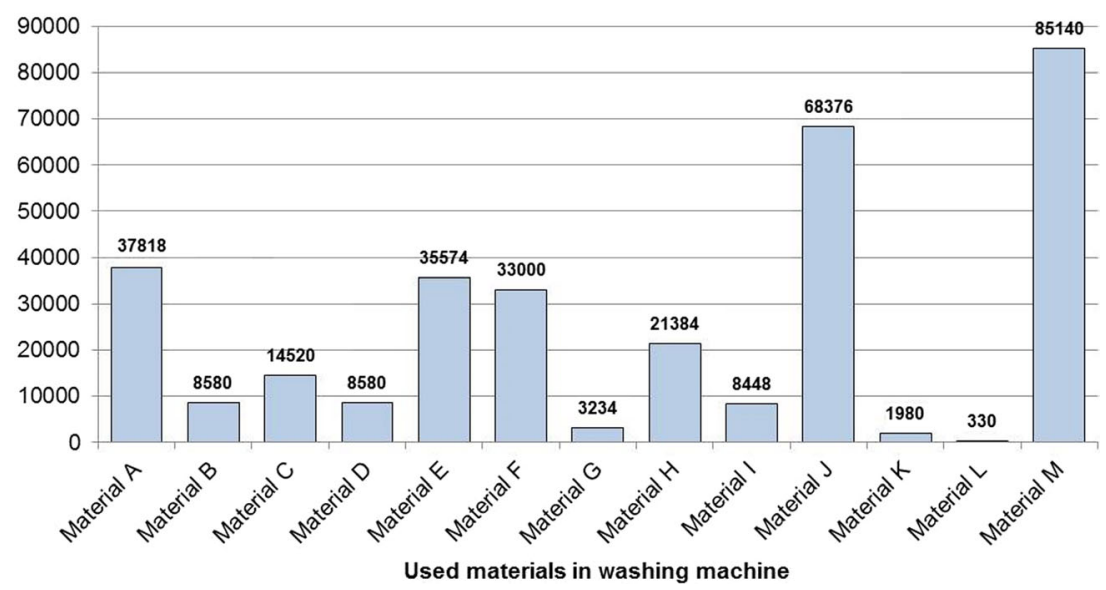


in industry with a reference point if and which circular design approach may be the best choice.

Another practical outcome of the tool is that the obtained result can be used as complementary input when it comes to product modularization. The grouping of functional clusters can further support operational excellence of circular systems at the EoL stage.

\section{Conclusions}

This paper provides researchers as well as practitioners with a quantitative analysis tool to explore design and CE business model combinations and optimize design to fit to a model of preference or choice. The tool delivers results based on planned design efforts, chosen end-of-life strategies of components (i.e., reuse, remanufacturing, recycling) in different business and supply chain settings. The tool serves as decision support at the intersection of product design, business model, and supply chain and is capable of connecting end-of-life design with business strategy.

Two developments constitute the core of this paper. The first is a systematic method for quantifying design efforts for different circular design options. The second is a multimethod model combining agent-based and discrete event simulation to model closed-loop manufacturing systems which are designed to close the loop by intention.

The combination of agent-based and discrete event approach allows for connecting design on component level with business strategy. Consequences of different design choices in circular supply chains can be systematically investigated since components and their data are traceable throughout the entire simulation time. Manufacturing system settings allow for considering different degrees of quality, quantity, and timing of product returns. As a result, cost, $\mathrm{CO}_{2}$, and material saving effects over time can be quantified using agent-based product architectures and discrete event supply chains. This significantly reduces uncertainty when it comes to evaluating circular design and business approaches at early design stage and leads to improved decision-making about circular system implementation.

Finally, this model may be extended and linked to aspects of marketing and customer demand variation [33] to include potential revenue streams in order to consider profitability of circular systems.

Open Access This article is distributed under the terms of the Creative Commons Attribution 4.0 International License (http:// creativecommons.org/licenses/by/4.0/), which permits unrestricted use, distribution, and reproduction in any medium, provided you give appropriate credit to the original author(s) and the source, provide a link to the Creative Commons license, and indicate if changes were made.

\section{References}

1. Rashid A, Asif FMa, Krajnik P, Nicolescu CM (2013) Resource conservative manufacturing: an essential change in business and technology paradigm for sustainable manufacturing. J Clean Prod 57:166-177

2. Asif FMA, Lieder M, Rashid A (2016) Multi-method simulation based tool to evaluate economic and environmental performance of circular product systems. J Clean Prod 139:1261-1281

3. Lieder M, Rashid A (2015) Towards circular economy implementation: a comprehensive review in context of manufacturing industry. J Clean Prod 115:36-51

4. Ou-Yang C, Lin TS (1997) Developing an integrated framework for feature-based early manufacturing cost estimation. Int J Adv Manuf Technol 13(9):618-629

5. Asiedu Y, Gu P (2010) Product life cycle cost analysis: state of the art review. Int J Prod Res 36(4):883-908

6. I. International Standard Organization, Environmental management—life cycle assessment-principles and framework, Geneva, Switzerland, 14040, 2006.

7. Deng C, Wu J, Shao X (2016) Research on eco-balance with LCA and LCC for mechanical product design. Int J Adv Manuf Technol 87(5-8):1217-1228

8. Kumaran DS, Ong SK, Tan RBH, Nee AYC (2001) Environmental life cycle cost analysis of products. Environ Manag Heal 12:260 276

9. Norris GA (2001) Integrating life cycle cost analysis and LCA. Int J Life Cycle Assess 6(2):118-120

10. Zarandi MHF, Mansour S, Hosseinijou SA, Avazbeigi M (2011) A material selection methodology and expert system for sustainable product design. Int J Adv Manuf Technol 57(9-12):885-903

11. Niazi A, Dai JS, Balabani S, Seneviratne L (2006) Product cost estimation: technique classification and methodology review. J Manuf Sci Eng 128(2):563-575

12. Lee SG, Lye SW, Khoo MK (2001) A multi-objective methodology for evaluating product end-of-life options and disassembly. Int $\mathbf{J}$ Adv Manuf Technol 18(2):148-156

13. Harjula T, Rapoza B, Knight WA, Boothroyd G (1996) Design for disassembly and the environment. CIRP Ann. - Manuf. Technol. 45(1):109-114

14. Zussman E, Kriwet A, Seliger G (1994) Disassembly-oriented assessment methodology to support design for recycling. CIRP Ann Manuf Technol 43(1):9-14

15. Soh SL, Ong SK, and Nee AYC (2014) Design for disassembly for remanufacturing: methodology and technology, in Procedia CIRP, $15: 407-412$

16. Go TF, Wahab DA, Hishamuddin H (2015) Multiple generation life-cycles for product sustainability: the way forward. J Clean Prod 95:16-29

17. N. Tchertchian, H. Liang, and D. Millet, The influence of multiple life cycles on the environmental impact of a product, in International Conference on Engineering Design (ICED), 2009, pp. 185-196.

18. Gu P, Sosale S (1999) Product modularization for life cycle engineering. Robot Comput Integr Manuf 15(5):387-401

19. Takakuwa S (1997) The use of simulation in activity-based costing for flexible manufacturing systems, in Proceedings of the 1997 Winter Simulation Conference, pp. 793-800.

20. Kendall K, Mangin C, and Ortiz E (1998) Discrete event simulation and cost analysis for manufacturing optimization of an automotive LCM component, Compos. Part A Appl. Sci. Manuf., vol. 29, no. Compendex, pp. 711-720

21. Spedding TA, Sun GQ (1999) Application of discrete event simulation to the activity based costing of manufacturing systems. Int $\mathrm{J}$ Prod Econ 58(3):289-301 
22. Cheng K, Srai JS (2012) Special issue on sustainable manufacturing and the key enabling technologies. Proc Inst Mech Eng Part B J Eng Manuf 226(10):1603-1603

23. Hatcher GD, Ijomah WL, Windmill JFC (2011) Design for remanufacture: a literature review and future research needs. J Clean Prod 19(17-18):2004-2014

24. He B, Tang W, Wang J, Huang S, Deng Z, Wang Y (2015) Lowcarbon conceptual design based on product life cycle assessment. Int J Adv Manuf Technol 81(5):863-874

25. Bocken NMP, Bakker C, and I. De Pauw, Product design and business model strategies for a circular economy, J. Ind. Prod. Eng., vol. 1015, no. 0, p. 20, 2016.

26. M. Moreno, C. De los Rios, Z. Rowe, and F. Charnley, A conceptual framework for circular design, Sustain., vol. 8, no. 9, 2016.

27. Sakai N, Tanaka G, and Shimomura Y (2003) Product life cycle design based on product life control, in Environmentally Conscious Design and Inverse Manufacturing, 2003. EcoDesign '03. 2003 3rd International Symposium on, pp. 102-108.
28. A. Borshchev and A. Filippov, From system dynamics and discrete event to practical agent based modeling: reasons, techniques, tools, in 22nd International Conference of the System Dynamics Society, 25-29 July 2004, 2004, p. 45.

29. F. M. Asif, C. Bianchi, A. Rashid, and C. M. Nicolescu, Performance analysis of the closed loop supply chain, J. Remanufacturing, vol. 2, no. 1, p. 4, 2012.

30. Siebers PO, Macal CM, Garnett J, Buxton D, Pidd M (2010) Discrete-event simulation is dead, long live agent-based simulation! J Simul 4(3):204-210

31. Vogtländer JG (2010) A practical guide to LCA for students, designers and business managers. First edit, VSSD

32. I. OptTek Systems, OptTek Systems, 2016. [Online]. Available: http://www.opttek.com/. [Accessed: 20-Dec-2016].

33. Lieder M, Asif FMA, Rashid A (2017) Towards circular economy implementation: an agent-based simulation approach for business model changes. Auton. Agent. Multi. Agent. Syst 